\title{
KARAKTERISTIK SIFAT SENSORIS MINUMAN SARI BUAH SALAK YANG DITAMBAHI PENGAWET ALAMI EKSTRAK KULIT MANGGIS (GARCINIA MANGOSTANA L.)
}

\author{
Setiani $^{1 *}$, Rakhmawati ${ }^{2}$, Askur Rahman ${ }^{2}$ \\ ${ }^{1}$ Prodi Agribisnis, Fakultas Pertanian, Universitas Trunojoyo Madura \\ ${ }^{2}$ Prodi Teknologi Industri Pertanian, Fakultas Pertanian, Universitas Trunojoyo Madura \\ Email: tianiyani@gmail.com
}

\begin{abstract}
Penambahan pengawet alami pada sari buah bertujuan untuk mencegah kerusakan pada minuman sari buah. Penambahan pengawet alami tentunya akan menyebabkan terjadinya perubahan sifat sensoris. Oleh sebab itu pengamatan sifat sensoris pada minuman sari buah salak diperlukan. Tujuan dari penelitian ini adalah untuk mengetahui karakteristik sensoris pada sari buah salah yang ditambahi pengawet ekstrak kulit buah manggis. Faktor yang digunakan yaitu konsentrasi ekstrak kulit manggis $(0 \% ; 1.5 \%$; $2.5 \% ; 3.5 \% ; 4.5 \%$ dan $5.5 \%$ ) yang akan ditambahkan dalam pembuatan sari buah salak. Karakteristik sensoris minuman sari buah salak menunjukkan nilai kesukaan paling tinggi pada atribut warna yaitu $3.17 \pm 0.65$, nilai aroma $3.13 \pm 0.63$, nilai rasa $3.27 \pm 0,78$ dan nilai keseluruhan $3.07 \pm 0.98$
\end{abstract}

Kata Kunci: Salak, Sari Buah, Kulit Manggis, Pengawet, Sensoris.

\section{PENDAHULUAN}

Minuman sari buah dibuat ddari sari buah-buahan dan air yang ditambahi atau tidak gula dan bahan lain yang diijinkan (Arinda dan Yunianta, 2015). Minuman sari buah salak dibuat dengan bahan baku buah salak (Salaca edulis Reinw.) yang merupakan komoditas buah indegenous Indonesia (Utama et al., 2006). Minuman sari buah salak mudah mengalami perubahan mutu (kerusakan) yang ditimbukan dengan bau alkohol, rasa asam, dan pembentukan gas. Menurut Sopandi dan Wardah (2014) mengatakan bahwa minuman buah rentan terhadap kerusakan oleh kapang, khamir, Lactobacillus, Leuconostoc, dan Acetobacter spp. Oleh sebab itu diperlukan upaya untuk mencegah kerusakan sari buah salak tersebut dengan cara teknologi pengawetan.

Upaya yang telah dilakukan untuk mencegah kerusakan pada minuman sari buah yaitu dengan cara pemanasan, pembekuan, refrigasi (Sopandi dan Wardah, 2014), penyinaran sinar ultraviolet-C (Arinda dan Yunianta, 2015), dan menggunakan pengawet Natrium benzoat (Subani, 2008). Namun, penggunaan teknologi dengan cara pemanasan, pembekuan, refrigasi, dan sinar ultraviolet-C membutuhkan investasi alat yang cukup mahal, sehingga tidak dapat dijangkau oleh industri kecil yang masih berkembang. Sedangkan penggunaan pengawet natrium benzoat memang diperbolehkan di dalam makanan, namun pada kenyataannya banyak ditemukan minuman sari buah yang melebihi batas yang ditentukan. Penelitian oleh Lembaga Konsumen Jakarta (LKJ) pada tahun 2011 menemukan beberapa minuman sari buah yang dijual di pasaran mengandung bahan pengawet berlebihan (2 kali melebihi batas maksimum). Oleh sebab itu diperlukan cara lain untuk mengawetkan sari buah salah satunya 
memanfaatkan bahan yang ada disekitar atau menggunakan limbah pertanian sebagai bahan pengawet.

Alternantif lain dalam mengatasi kerusakan minuman sari buah yaitu pengawet alami. Salah satu kelebihan penggunaan pengawet alami yaitu lebih aman untuk kesehatan. Berbahagai bahan pengawet alamiah telah dieksplorasi seperti pengawet alamiah dari daun jambu, cabe, kayu manis, bawang, daun sirih, dan lain-lain. Salah satu bahan yang potensial untuk dijadikan pengaet pada sari buah salak adalah kulit manggis. Kulit buah manggis seringkali dibuang begitu saja, sehingga menjadi sampah yang tidak memiliki nilai ekonomis. Padahal dalam kulit manggis mrngandung secawa xanton, mangostin, garsinon, flavonoid dan tanin (Heyne, 1987 dalam Naufalin et al., 2013). Kandungan senyawa tersebut pada kulit buah manggis memiliki aktivitas antimikroba dan antioksidan (Naufalin dan Herastuti, 2012). Putra (2010) menambahkan bahwa antrakuinon merupakan komponen yang dominan dalam fraksi kloroform ekstrak metanol kulit buah manggis yaitu $57.13 \%$. Senyawa tersebut diduga sebagai komponen antrimikroba kunci dalam fraksi tersebut.

Penambahan pengawet alami pada minuman sari buah salak tentunya akan menyebabkan terjadinya perubahan fisik, kimia maupun sensoris. Perubahan sifat tersebut penting untuk diketahui terutama sifat sensoris. Sifat sensoris sering dikaitkan dengan pengukuran tingkat daya terima maupun kesukaan panelis terhadap produk hasil inovasi baru. Hal itu penting untuk dilakukan karena akan memberikan informasi sejauh mana produk yang dikembangkan dapat diterima oleh konsumen. Oleh sebab itu dalam penelitian ini dilakukan pengujian sifat sensoris pada minuman sari buah salak dengan menggunakan metode uji kesukaan oleh panelis.

\section{METODE}

\section{Bahan}

Bahan baku dalam penelitian ini adalah kulit buah manggis (Garcinia mangostana L.) dari buah manggis yang masak optimal. Kulit buah manggis diperoleh dari pasar Kecamatan Kamal dan pasar Kyi Lemah Duwur Kabupaten Bangkalan. Buah Salak diperoleh dari petani di Desa Bilepora Kecamatan Socah Kabupaten Bangkalan.

\section{Tahapan penelitian}

1. Pembuatan Ekstrak Kulit Buah Manggis

Pembuatan ekstrak Kulit Buah Manggis mengacu Dyahnugra dan Widjanarko (2015) yang dimodifikasi yaitu kulit buah manggis yang telah dipisahkan dari daging buah dan kulit luar yang keras, dipotong kecil ukuran 0.50 $\mathrm{cm} 2$ kemudian dikeringkan dengan menggunakan oven listrik suhu 50OC selama 6 jam. Kulit yang kering dihaluskan dengan blender hingga menjadi bubuk yang selanjutnya diayak menggunakan ayakan ukuran 60 mesh sehingga diperoleh bubuk simplisia kulit manggis. Ekstraksi dilakukan dengan cara merendam bubuk simplisia kulit manggis dalam pelarut air dengan perbandingan 1:6 selama 24 jam pada suhu ruang $\left(25-27^{\circ} \mathrm{C}\right)$. Setelah proses maserasi berakhir, dilakukan penyaringan hingga didapatkan filtrat dan dipekatkan dengan rotary evaporator pada tekanan 60 mBar suhu $50^{\circ} \mathrm{C}$.

\section{Pembuatan Sari Buah Salak}

Buah salak dikupas terlebih dahulu, setelah itu buah salak dipisahkan dari bijinya. Setelah buah salak dipisahkan dari bijinya lalu buah salak dicuci sampai bersih. Selanjutnya buah salak diblender dan ditambahkan air dengan perbandingan $1 \mathrm{~kg}$ buah salak dicampur dengan 3 liter air. Setelah proses pemblenderan selesai, adonan salak direbus sampai lembut. Apabila adonan salak yang direbus sudah lembut maka buah salak ditiriskan. 
Selanjutnya adonan salak dicampur dengan gula pasir, gula yang dicampurkan sebanyak 1.5 ons. Selanjutnya adonan salak yang sudah dicampur dengan gula direbus kembali hingga mendidih. Setelah adonan salak mendidih, adonan salak disaring ditambahkan ekstrak kulit manggis (konsentrasi 1.5\%; $2.5 \% ; 3.5 \%$; $4.5 \%$ dan $5.5 \%$ ) dan didinginkan. Selanjutnya dikemas dengan menggunakan kemasan plasti cup.

3. Uji Sensoris

Uji sensoris dilakukan dengan uji hedonic (tingkat kesukaan) terhadap tekstur, warna, rasa dan aroma. Panelis yang digunakan sebanyak 30 orang panelis yang tidak terlatih.

\section{HASIL DAN PEMBAHASAN}

Pengujian sifat sensoris digunakan untuk mengetahui kesukaan dan daya terima panelis terhadap minuman sari buah salak yang ditambahi pengawet alami. Menurut Setyaningsih et al. (2010) uji sensoris merupakan pengujian dengan menggunakan indera untum menilai kualitas dan kemanan suatu makanan atau minuman. Tujuan uji sensoris untuk mengetahui respon atau kesan yang diperoleh pancaindera manusia terhadap suatu rasngsangan yang ditimbulkan oleh suatu produk. Hasil pengujian sifat sensoris dari sari buah salak yang ditambahi dengan pengawet alami ekstrak kulit manggis dapat dapat dijelaskan sebagai berikut.

\section{Tingkat Kesukaan Warna Minuman Sari Buah Salak}

Kenampakan pada suatu produk penting untuk diperhatikan, karena keinginan konsumen untuk membeli suatu produk biasanya dipengaruhi oleh kenampakan suatu produk. Salah satu atribut dari kenampakan yaitu warna. Menurut Meilgaard et al. (1999) suatu fenomena yang melibatkan baik komponen fisik maupun psikologis untuk menerima persepsi cahaya dengan panjang gelombang 400-500 nm (biru), 500-600 nm (hijau dan kuning), dan nilai 600-800 $\mathrm{nm}$ (merah) sering diistilahkan sebagai nilai hue, dan kroma dari sistem warna Munsell.

Warna pada suatu bahan dipengaruhi oleh pigmen yang terkandung pada suatu bahan. Pada minuman sari buah salak yang ditambahi pengawet alami warnanya menjadi agak kemerahan dengan semakin ditambahnya konsetrasi pengawet alami kulit manggis. Perubahan tersebut dipengaruhi oleh kandungan pigmen yang terkandung pada kulit manggis yaitu pigmen antosianin (Permana, 2010; Supiyanti et al. 2010; Nayak et al. 2010; Cheoka et al. 2013; Azima et al. 2017). Hasil pengujian kesukaan warna (Gambar 1) menggunakan panelis menunjukkan bahwa panelis lebih menyukai waran dengan konsentrasi pengawet alami 3.5\%. 


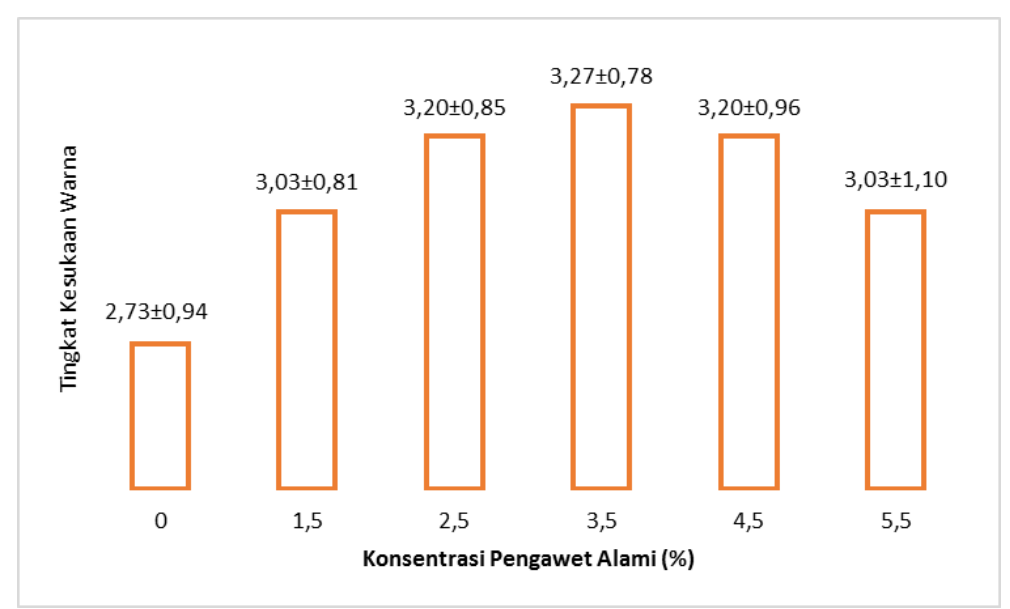

Gambar 1. Tingkat Kesukaan Warna Minuman Sari Buah Salak

Tingkat Kesukaan Aroma Minuman Sari Buah Salak

Atribut aroma pada suatu produk sesungguhnya sifat sensoris yang paling sulit untuk diklasifikasikan dan dijelaskan karena ragamnya yang terlalu besar (Setyaningsih et al. 2010). Wahono (2006) menjelaskan bahwa aroma timbul dari senyawa volatil yang terbebas dari suatu produk pangan saat produk tersebut berada dalam mulut sehingga terdeteksi oleh sistem penciuman yang ada dihidung. Mekanisme munculnya prsepsi aroma yaitu senyawa volatil ditrasmisikan oleh suatu medium pembawa (gas, atmosfer atau uap air) untuk mencapai Atribut aroma pada suatu produk sesungguhnya sifat sensoris yang paling sulit untuk diklasifikasikan dan dijelaskan karena ragamnya yang terlalu besar (Setyaningsih et al. 2010). Wahono (2006) menjelaskan bahwa aroma timbul dari senyawa volatil yang terbebas dari suatu produk pangan saat produk tersebut berada dalam mulut sehingga terdeteksi oleh sistem penciuman yang ada dihidung. Mekanisme munculnya prsepsi aroma yaitu senyawa volatil ditrasmisikan oleh suatu medium pembawa (gas, atmosfer atau uap air) untuk mencapai hidung, kemudian dideteksi oleh sel-sel penerima yang ada di hidung. Informasi tesebut kemudian dikirim ke otak kecil, lalu dilanjutkan ke otak kecil membentuk suatu persepsi yang akhirnya akan dirubah menjadi respon aroma.

Hasil uji kesukkan pada minuman sari buah salak yang ditambahi pengawet alami (Gambar 2) menunjukkan bahwa panelis lebih suka pada minuman dengan pengawet alami $1.5 \%$. Hal itu menunjukkan bahwa peningkatan konsetrasi pengawet alami pada minuman sari buah salak tidak terjadi peningkatan kesukaan secara signifikan. Kondisi terbut dipengaruhi oleh kandungan senyawa aromatik pada buah salak. Afrianti et al. (2010) menjelaskan bahwa pada buah salak terdapat senyawa aromatik seperti flavonoid yang juga berfungsi sebagai antioksidan. 


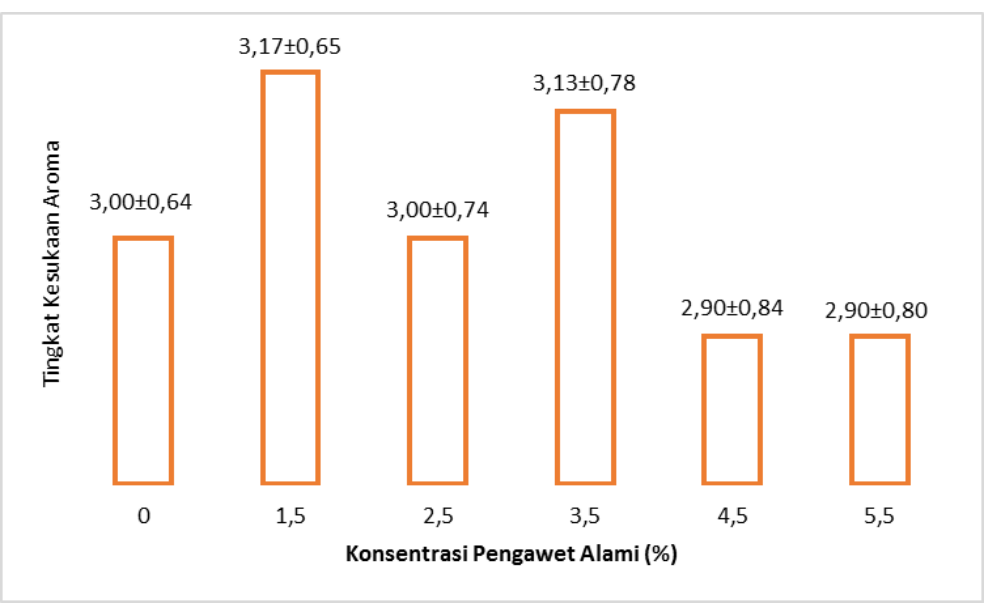

Gambar 2. Tingkat Kesukaan Aroma Minuman Sari Buah Salak

Tingkat Kesukaan Rasa Minuman Sari Buah Salak

Rasa merupakan persepsi atas hasil dari mencicipi (asin, manis, asam, pahit) disebabkan oleh adanya zat yang larut di dalam mulut (Meilgaard et al. 1999). Minuman sari buah memiliki karakteristik minuman yang dominan rasa manis. Rasa manis timbul dari penambahan gula pada saat proses produksi. Menurut Triyono (2010) rasa manis adalah salah satu dari lima sifat dasar dan hampir secara universal dianggap sebagai rasa yang disukai. Beberapa monosakarida dan disakarida mempunyai rasa manis sehingga sering kali digunakan sebagai bahan pemanis.

Hasil pengujian kesukaan rasa pada produk minuman sari buah salak yang ditambahi pengawet alami (Gambar 3) menunjukkan bahwa perlakuan penambahan pengawet alami yang disukai yaitu pada konsentrasi $4.5 \%$. Namun secara statistik tidak terjadi perbedaan yang signifikan antar perlakuan.

\section{Tingkat Kesukaan Keseluruhan Minuman Sari Buah Salak}

Secara statistik tingkat kesukaan secara keseluruhan minuman sari buah salak yang ditambahkan pengawet alami kulit manggis tidak menunjukkan adannya pengaruh nyata pada taraf 5\%. Hal ini disebabkan oleh kecenderungan panelis memberikan penilaian yang hampir sama pada semua perlakuan. Namun secara nilai menunjukkan penambahan pengawet alami dari kulit manggis $1.5 \%$ memiliki nilai kesukkan tertinggi $(3.13 \pm 0.63)$. Hal ini dikarenakan semakin meningkatnya konsetrasi pengawet alami dari ekstrak kulit manggis menyebabkan terjadi perubahan warna yang akan semakik merah gelab, sehingga panelis memberikan respon kurang suka sampai pada level $1.5 \%$. 


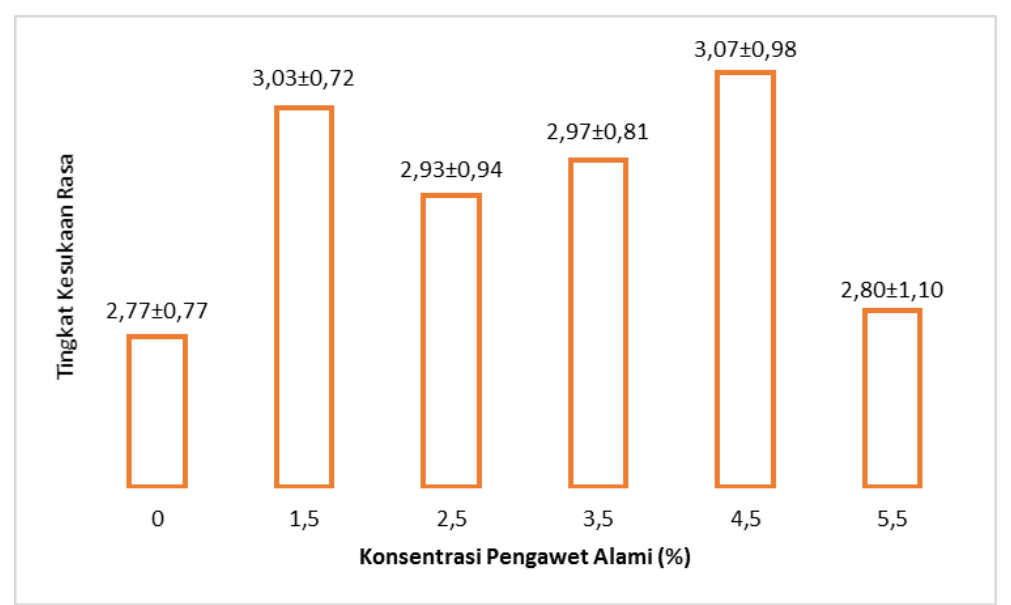

Gambar 3. Tingkat Kesukaan Rasa Minuman Sari Buah Salak

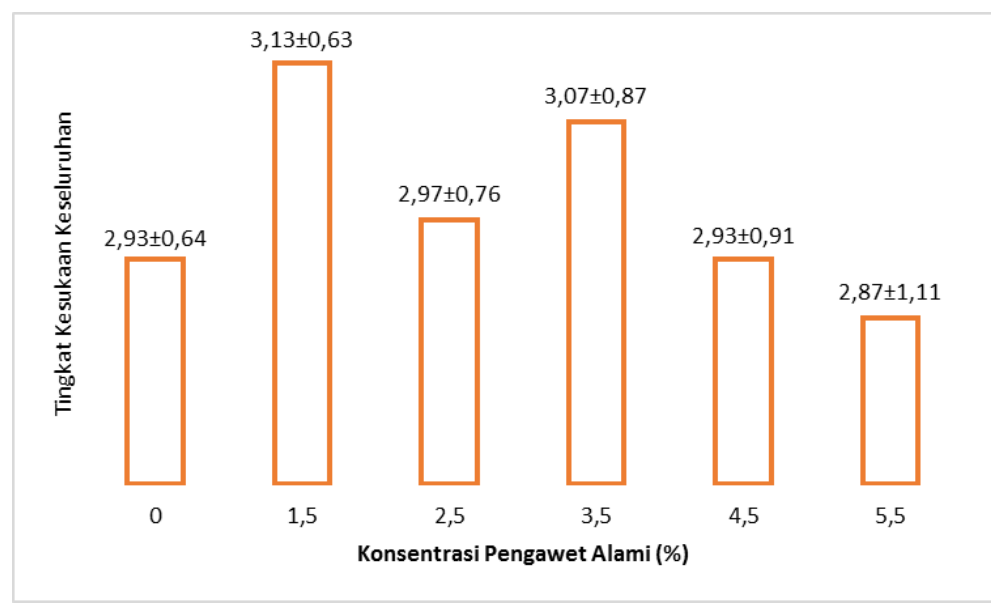

Gambar 4. Tingkat Kesukaan Keseluruhan Minuman Sari Buah Salak

\section{KESIMPULAN}

Karakteristik sensoris minuman sari buah salak menunjukkan nilai kesukaan paling tinggi pada atribut warna yaitu $3.17 \pm 0.65$, nilai aroma $3.13 \pm 0.63$, nilai rasa $3.27 \pm 0.78$ dan nilai keseluruhan $3.07 \pm 0.98$.

\section{UCAPAN TERIMAKASIH}

Ucapan terimakasih disampaikan kepada Direktorat Riset dan Pengabdian Masyarakat, Dirjen Penguatan Riset dan Pengembangan, KEMENRISTEKDIKTI dalam pembiayaan melalui skema Penelitian Dosen Pemula (PDP) tahun anggaran 2017.

\section{DAFTAR PUSTAKA}

Afrianti, L.H.; E.Y. Sukandar; S. Ibrahim; dan I.K. Adnyana. Senyawa Asam 2Metilester-1-H-Pirol-4-Karboksilat dalam Ekstrak Etil Asetat Buah Salak Varietas Bongkok sebagai Antioksidan dan Antihyperuricemia. J.Teknol. dan Industri Pangan, Vol. 21. No. 1. Hal. 66-72.

Arinda, I.D., dan Yunianta. 2015. Pengaruh Daya dan Lama Penyinaran Sinar Ultraviolet-C Terhadap Total Mikroba Sari Buah Salak Pondoh. Jurnal Pangan dan Agroindustri Vol. 3 No 4 Hal.1337-1344. 
Azima, A.M.S.; A. Noriham; dan N. Manshoor. 2017. Phenolics, antioxidants and color properties of aqueous pigmented plant extracts: Ardisia colorata var. elliptica, Clitoria ternatea, Garcinia mangostana and Syzygium cumini. Journal of Functional Foods. Vol. 38 Hal. 232241

Cheoka, C.Y.; N.L. China; Y.A. Yusofa; R.A. Taliba; dan C.L. Lawb. 2013. Optimization of total monomeric anthocyanin (TMA) and totalphenolic content (TPC) extractions from mangosteen (Garciniamangostana Linn.) hull using ultrasonic treatments. J Industrial Crops and Products. Vol 50 Hal. 1-7

Dyahnugra, A.A. dan S.B. Widjanarko. 2015. Pemberian Ekstrak Bubuk Simplisia Kulit Manggis (garcinia mangostana L.) Menurunkan Kadar Glukosa Darah pada Tikus Putih (Rattus norvegicus) Strain Wistar Jantan Kondisi Hiperglikemik. Jurnal Pangan dan Agroindustri. Vol. 3 No 1 Hal.113-123.

Meilgaard, M.; Civille, G.V.; dan Carr, B.T. 1999. Sensory Evaluation Techniques. CRC Press. Boca Raton.

Naufalin R dan Herastuti SR. 2012. Pengawet alami pada produk pangan. Unsoed Press. Purwokerto

Naufalin, R.; T. Yanto dan A. Sulistyaningrum. 2013. Pengaruh Jenis dan Konsentrasi Pengawet Alami Terhadap Mutu Gula Kelapa. Jurnal Teknologi Pertanian Vol. 14 No. 3 Hal. 165-174.

Nayak, C.A; P. Srinivas dan N.K. Rastogi. 2010. Characterisation of anthocyanins from Garcinia indica Choisy. J. Food Chemistry. Vol. 118 Hal. 719-724
Permana, A.W. 2010. Kulit Buah Manggis Dapat Menjadi Minuman Instan Kaya Antioksidan.Warta Peneltian dan Pengembangan Pertanian. Vol. 32 No. 2. BBP2TP. Badan Litbang.Kementan RI. Indonesia

Putra, I.N.K. 2010. Aktivitas Antibakteri Ekstrak Kult Buah Manggis (Garcinia mangostana L) serta Kandungan Senyawa Aktifnya. Jurnal Teknol. dan Industri Pangan Vol.21 No. 1 Hal. 1-5.

Setyaningsih, D., Anton, A., dan Maya, P.S. 2010. Analisis Sensori untuk Industri Pangan dan Agro. IPB Press. Bogor.

Sopandi, T. dan Wardah. 2014. Mikrobiologi Pangan. ANDI Yogyakarta. Yogyakarta.

Subani. 2008. Penentuan Kadar Natrium Benzoat, Kalium Sorbat dan Natrium Sakarin dalam Sirup dengan Metode Kromatografi Cair Kinerja Tinggi (KCKT) di Balai Besar Pengawasan Obat dan Makanan. Medan. USU Medan.

Supiyanti, W; E.D Wulansari dan L. Kusmita. 2010. Uji Aktivitas Antioksidan dan Penentuan Kandungan Antosianin Total Kulit Buah Manggis (Garcinia mangostana L). Majalah Obat Tradisional, Vol. 15 No. 2, Hal. $64-70$.

Triyono, A. 2010. Pengaruh Konsentrasi Ragi Terhadap Karakteristik Sari Buah dari Beberapa Varietas Pisang (Musa paradisiaca L). Prosiding Seminar Nasional Teknik Kimia "Kejuangan" Pengembangan Teknologi Kimia untuk Pengolahan Sumber Daya Alam Indonesia. Yogyakarta, 26 Januari 2010

Utama, I.M.S; I. B. P. Gunadnya dan L. P. Wrasiati. 2006. Pengaruh Etanol Terhadap Kadar Tanin, Total Padatan Terlarut dan Total Asam Daging Buah 
Salak. Jurnal Agritrop. Vol. 25. No.2

Hal 1-11.

Wahono, T. 2009. Dasar-dasar Uji Indrawi.

Fakultas Teknologi Pertanian.

Universitas Brawijaya. Malang. 